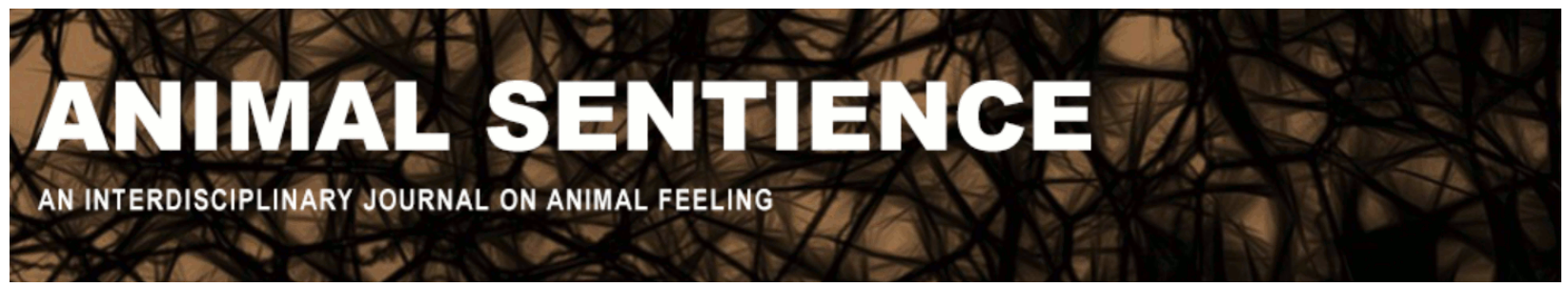

da Silva, Marissol Leite; Maximino, Caio; and Siqueira-Silva, Diógenes Henrique (2018) Nocifensive behavior as evidence for sentient pain in fish. Animal Sentience 21(15)

DOI: $10.51291 / 2377-7478.1365$

Date of submission: 2018-08-13

Date of acceptance: 2018-08-28

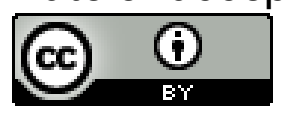




\title{
Nocifensive behavior as evidence for sentient pain in fish
}

Commentary on Sneddon et al. on Sentience Denial

\author{
Marissol Leite da Silva ${ }^{1,2,3}$, Caio Maximino ${ }^{2,4,5}$, \& Diógenes Henrique Siqueira-Silva ${ }^{2,3,4}$ \\ ${ }^{1}$ Undergraduate in Biology, Universidade Federal do Sul e Sudeste do Pará (Unifesspa), Brazil \\ ${ }^{2}$ Laboratório de Neurociências e Comportamento, Instituto de Estudos em Saúde e \\ Biológicas, Universidade Federal do Sul e Sudeste do Pará, Brazil \\ ${ }^{3}$ Grupo de Estudos da Reprodução de Peixes Amazônicos, Universidade Federal do Sul e \\ Sudeste do Pará, Brazil \\ ${ }^{4}$ Programa de Pós-Graduação em Biodiversidade e Biotecnologia - Rede BIONORTE, Brazil \\ ${ }^{5}$ Programa de Pós-Graduação em Neurociências e Comportamento, Universidade Federal do \\ Pará, Brazil
}

\begin{abstract}
Fish nocifensive behavior can be studied and understood similarly to the way pain is studied and understood in more advanced vertebrates. Nocifensive behavior is a behavioral and physiological response to a noxious stimulus that leads to the fish avoiding it in the future. This behavioral flexibility is an important criterion for inferring pain sentience in fish. Modulation of the nocifensive behavior by anxiety, fear, or stress has already been demonstrated in zebrafish. The affective experiences of fish will not be identical to those of human beings, clearly. Empirical research will need to ascertain how similar they are.
\end{abstract}

Marissol Leite da Silva, undergraduate in Biology at Universidade Federal do Sul e Sudeste do Para, assesses anesthesia in fish using alternative extracts of native plants. https://labit.io/lab/62/home

Caio Maximino develops behavioral models for neuroscience studies in zebrafish, with a special interest in fear, anxiety, stress, and pain. $\mathrm{He}$ is an Associate Professor of anatomophysiology at Universidade Federal do Sul e Sudeste do Pará.

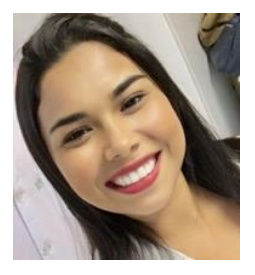

https://labit.io/lab/62/home

Diógenes Henrique de Siqueira-Silva, PhD in Animal Biology, Professor in Universidade Federal do Sul e Sudeste do Para, works on biotechnology applied to fish reproduction. https://www.researchgate.net/profile/Diogenes SiqueiraSilva2
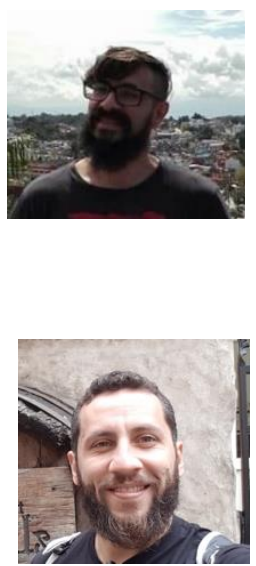


\section{Introduction}

Sneddon et al. (2018) makes interesting points on whether fish nocifensive behavior is qualitatively similar to pain in vertebrates with bigger brains, including humans. They summarize their own research on pain, behavioral flexibility, and cognition in different fish species to support arguments about whether fish are sentient, whether they feel pain and what it is like to feel pain. The authors appeal to Broom's (2014) criteria for sentience, which include the ability to experience positive and negative emotions. The recourse to sentience is part of a tradition in welfare research that equates suffering and pain with subjective distress, and therefore with the capacity for feeling: pain is generally viewed from the human perspective, highly associated with subjective feelings and negative valence, and hence with brain activity and its role in conscious function (Allen et al. 2005; Broom 2007, 2014; Shettleworth 2009; Shriver 2006). In humans, the link between a felt state such as pain and its underlying brain responses can be established by combining neuroimaging techniques with a verbal report of pain (Rose 2002). In fish, however, the link is more difficult to demonstrate. Moreover, important disanalogies exist because the brain regions typically associated with conscious experiences in humans - including cortical regions - are either absent or reduced in fish (Key 2016; Northcutt 2011).

\section{Nocifensive Behavior as Evidence for Sentient Pain}

Sneddon et al. are well aware of the limited applicability in fish of the traditional approach to ascertaining pain in vertebrates. That is why they review the extensive evidence, much of it gathered by themselves. In all the cases they discuss, pain is demonstrated with both a physiological response, such as inflammation, and behavioral reaction to the stimulus (nocifensive behavior) (Dawkins 2006; Mendl \& Paul 2004, 2008; Paul et al. 2005). Pain can be defined as an unpleasant sensory and emotional experience associated with actual or potential tissue damage (IASP Task Force on Taxonomy 1994). In addition to showing that a noxious stimulus induces nocifensive behavior, it must be shown that the animal learns that the stimulus is unpleasant and avoids it in future (Sneddon et al. 2003): The animal must be able to show behavioral flexibility.

Sneddon et al. (2003) demonstrated such responses in the rainbow trout, Oncorhynchus mykiss. Specimens stimulated with $1 \%$ acetic acid significantly increased their rate of opercular beats and showed anomalous swimming behavior, moving from side to side balancing on the pectoral fin while resting on the bottom. They also scratched their lips into the gravel and against the tank walls. Twenty-two nociceptive regions could be identified on the face and head of that species when skin was stimulated by noxious heat. In zebrafish (Danio rerio), specimens likewise increased their opecular beat rate and tended to occupy the bottom of tank after a tail fin clip (Schroeder \& Sneddon 2017) or injection of $1 \%$ acetic acid to the tail (Maximino 2011). Moreover, in that study, the authors demonstrated that lidocaine and acetylsalicylic acid had analgesic effects, reducing the abnormal behavioral and physiological response after fish surgery. Schroeder and Sneddon thus suggested that the increasing opercular beat rate is a distress signal that can be linked with noxious and painful events in some species. 


\section{"Top-Down" Modulation of Nocifensive Behavior in Fish}

Behavioral flexibility is an important criterion for inferring that fish feel pain. However, another important point, one not yet resolved by demonstrating that fish display nocifensive behavior, concerns the distinction between nociception and pain: Because nociceptors and nocifensive behavior can also be observed in a very wide range of species (including invertebrates such as Aplysia californica; Walter 1996), many of which seem unlikely to display sentience or other subjective states, the presence of nocifensive behavior alone provides little or no direct evidence of pain; this is the core of the "nocifensive behavior as reflex" argument. However, the "top-down" modulation of nociception by brain signals provides space for the distinction between felt pain (that is, sentient pain) and nociception. Allen et al. (2005) and Shriver (2006) argue that the dissociability between affective and sensory pain provides a potential route to empirical assessment of sentient pain; and Farah (2008) uses this distinction to separate suffering from "mere pain". The sensory-discriminative function of pain (i.e., the "what" and "where" information that is conveyed and can be processed mostly at the spinal level) is qualitatively different from the affective function that motivates the animal to attend (or not) to the noxious stimulus, and is processed in brain regions associated with emotion and motivation (Auray et al., 2008). In this sense, affective pain "hurts", while sensory pain can be dealt with at the level of the spinal reflex.

Interesting evidence for this top-down modulation comes from our own previous work, in which we show modulation of nocifensive behavior by anxiety, fear, or stress states in zebrafish (Lima et al. 2012; Maximino 2011; Maximino et al. 2014). We have shown that confinement stress (Maximino 2011) or an alarming substance (Maximino 2011; Maximino et al. 2014), which induces fear-like responses, inhibits nocifensive behavior. In contrast, environmental novelty (Maximino 2011), which induces anxiety-like responses, increases nocifensive behavior. Lopez-Luna et al. (2017) reported similar responses in zebrafish larvae. Wolkers et al. (2013; 2015a) $\square$ showed that the opioidergic and cannabinoid systems contributed to stress-induced antinociception in the piauçu, Leporinus macrocephalus. They also showed that the dorsomedial telencephalon, the homologue of the mammalian limbic associative amygdalar system (Maximino et al. 2013) $\square$ is needed for stress-induced antinociception (Wolkers et al. 2015b) $\square$

In general, these observations strengthen the idea of top-down modulation of nocifensive behavior in fish, and hence of felt pain. It is possible to find contrary opinions in the literature. Rose (2002) $\square$ Key (2016) $\square$ land Stevens and colleagues (2016) $\square$ bssume that the lack of the neural structures associated with consciousness in humans makes fish unable to feel pain. However, Broom's (2014) $\square$ criteria for sentience, as Martin \& Gerlai (2018) $\square$ state, imply a continuum rather than binary responses. The evolutionary history of brain systems associated with pain, moreover, allows for parallel evolution of different mechanisms to support felt pain (Striedter 2016); and indeed there is a good deal of evidence on neurobehavioral mechanisms that support both sensory and affective pain in fish (for reviews, see Braithwaite et al. 2011; Demski 2013; Kalueff et al. 2012; Kittilsen 2013; Woodruff 2017) $\square$ The affective experiences of fish are certainly not identical to those of human beings, but, as Martin \& Gerlai put it, the question is not whether or not neurobehavioral systems are identical, but "how similar is this feeling to what humans feel?" This is a question for empirical research. 


\section{References}

Allen, C., Fuchs, P. N., Shriver, A., \& Wilson, H. (2005). Deciphering animal pain. In Pain: New essays on the nature of pain and the methodology of its study (pp. 352-366). Cambridge: MIT Press.

Auray, M., Myin, E., \& Spence, C. (2008). The sensory-discriminative and affectivemotivational aspects of pain. Neuroscience \& Biobehavioral Reviews, 34, 214-223.

Braithwaite, V. A., Huntingford, F., \& van den Bos, R. (2011). Variation in emotion and cognition among fishes. Journal of Agricultural and Environmental Ethics, 19, 7-23.

Broom, D. M. (2007). Cognitive ability and sentience: Which aquatic animals should be protected. Diseases of Aquatic Organisms, 75, 99-108.

Broom, D. M. (2014). Sentience and animal welfare. Wallingford: CABI.

Dawkins, M. S. (2006). Through animal eyes: What animal behaviour tells us. Applied Animal Behaviour Science, 100, 4-10.

Demski, L. S. (2013). The pallium and mind/behavior relationships in teleost fishes. Brain, Behavior and Evolution, 82, 31-44.

Farah, M. J. (2008). Neuroethics and the problem of other minds: Implications of neuroscience for the moral status of brain-damaged patients and nonhuman animals. Neuroethics, 1, 9-18.

IASP Task Force on Taxonomy. (1994). Part III: Pain terms, a current list with definitions and notes on usage. In H. Merskey \& N. Bogduk (Eds.), Classification of chronic pain (2nd ed., pp. 209-214). Seattle: IASP Pres.

Kalueff, A. V, Stewart, A. M., Kyzar, E. J., Cachat, J., Gebhardt, M., Landsman, S., ... International Zebrafish Neuroscience Research Consortium (ZNRC). (2012). Time to recognize zebrafish "affective" behavior. Behaviour, 149, 1019-1036.

Key, B. (2016). Why fish do not feel pain. Animal Sentience 3(1).

Kittilsen, S. (2013). Functional aspects of emotions in fish. Behavioural Processes, 100, 153159.

Lima, M. G., Maximino, C., Batista, E. de J. O., Oliveira, K. R. M., \& Herculano, A. M. (2012). Nocifensive behavior in adult and larval zebrafish. In A. V. Kalueff \& A. M. Stewart (Eds.), Zebrafish protocols for neurobehavioral research (Vol. 66). New York: Humana Press.

Lopez-Luna, J., Al-Jubouri, Q., Al-Nuaimy, W., \& Sneddon, L. U. (2017). Impact of stress, fear and anxiety on the nociceptive responses of larval zebrafish. PLOS ONE, 12, e0181010.

Martin, L., \& Gerlai, R. (2018). Sentience: All or none or matter of degree. Animal Sentience 21(9).

Maximino, C. (2011). Modulation of nociceptive-like behavior in zebrafish (Danio rerio) by environmental stressors. Psychology \& Neuroscience, 4, 149-155.

Maximino, C., Lima, M. G., Costa, C. C., Guedes, I. M. L., \& Herculano, A. M. (2014). Fluoxetine and WAY 100,635 dissociate increases in scototaxis and analgesia induced by conspecific alarm substance in zebrafish (Danio rerio Hamilton 1822). Pharmacology, Biochemistry, and Behavior, 124C, 425-433.

Maximino, C., Lima, M. G., Oliveira, K. R. M., Batista, E. de J. O., \& Herculano, A. M. (2013). "Limbic associative" and "autonomic" amygdala in teleosts: A review of the evidence. Journal of Chemical Neuroanatomy, 48-49, 1-13.

Mendl, M., \& Paul, E. S. (2004). Consciousness, emotion and animal welfare: Insights from cognitive science. Animal Welfare, 13, 17-25. 
Mendl, M., \& Paul, E. S. (2008). Do animals live in the present? Current evidence and implications for welfare. Applied Animal Behaviour Science, 113, 357-382.

Northcutt, R. G. (2011). Do teleost fishes possess a homolog of mammalian isocortex? Brain, Behavior and Evolution, 78, 136-138.

Paul, E. S., Harding, E. J., \& Mendl, M. (2005). Measuring emotional processes in animals: The utility of a cognitive approach. Neuroscience \& Biobehavioral Reviews, 29, 469-491.

Rose, J. D. (2002). The neurobehavioral nature of fishes and the question of awareness and pain. Reviews in Fisheries Science, 10, 1-38.

Schroeder, P. G., \& Sneddon, L. U. (2017). Exploring the efficacy of immersion analgesics in zebrafish using an integrative approach. Applied Animal Behaviour Science, 187, 93-102.

Shettleworth, S. J. (2009). Cognition, evolution and behavior (2nd ed.). Oxford: Oxford University Press.

Shriver, A. (2006). Minding mammals. Philosophical Psychology, 19, 433-442.

Sneddon, L. U., Braithwaite, V. A., \& Gentle, M. J. (2003). Novel object test: Examining nociception and fear in the rainbow trout. Journal of Pain, 4, 431-440.

Sneddon, L. U., Lopez-Luna, J., Wolfenden, D. C. C., Leach, M. C., Valentim, A. M., Steenbergen, P. J., Bardine, N., Currie, A. D., Broom, D. M., \& Brown, C. (2018). Fish sentience denial: Muddying the waters. Animal Sentience 21(1).

Stevens, E. D., Arlinghaus, R., Browman, H. I., Cooke, S. J., Cowx, I. G., Diggles, B. K., Key, B., Rose, J. D., Sawynok, W., Schwab, A., Skiftesvik, A. B., Watson, C. A., \& Wynne, C. D. L. (2016). Stress is not pain. Comment on Elwood and Adams (2015) 'Electric shock causes physiological stress responses in shore crabs, consistent with prediction of pain'. Biology Letters, 12, 20151006.

Striedter, G. F. (2016). Lack of neocortex does not imply fish cannot feel pain. Animal Sentience 3(15).

Walters, E. T. (1996). Comparative and evolutionary aspects of nociceptor function. In C. Belmonte \& F. Cervero (Eds.), Neurobiology of nociceptors (pp. 92-114). New York: Oxford University Press.

Wolkers, C. P. B., Barbosa, Jr., A., Menescal-de-Oliveira, L., \& Hoffmann, A. (2013). Stressinduced antinociception in fish reversed by naloxone. PLOS ONE, 8, e7115.

Wolkers, C. P. B., Barbosa, Jr., A., Menescal-de-Oliveira, L., \& Hoffmann, A. (2015a). Acute administration of a cannabinoid CB1 receptor antagonist impairs stress-induced antinociception in fish. Physiology \& Behavior, 142, 37-41.

Wolkers, C. P. B., Barbosa, Jr., A., Menescal-de-Oliveira, L., \& Hoffmann, A. (2015b). GABA $A_{A^{-}}$ benzodiazepine receptors in the dorsomedial ( $\mathrm{Dm}$ ) telencephalon modulate restraintinduced antinociception in the fish Leporinus macrocephalus. Physiology \& Behavior, 147, 175-182.

Woodruff, M. L. (2017). Consciousness in teleosts: There is something it feels like to be a fish. Animal Sentience 13(1). 